\title{
PROPOSTA DE IMPLEMENTAÇÃO DE PLANOS DE BENEFÍCIOS E INCENTIVOS PARA A REDUÇÃO DO ABSENTEÍSMO: ESTUDO DE CASO NA EMPRESA PEDRO PORTELLA NUNES EPP
}

\section{ARTIGO ORIGINAL}

CARVALHO, Amanda Sousa de ${ }^{1}$, SILVA, Clemilton Ferreira da ${ }^{2}$, SANTOS, Fabricio Lopes dos ${ }^{3}$, ROBERTO, José Carlos Alves ${ }^{4}$

CARVALHO, Amanda Sousa de. Et al. Proposta De Implementação De Planos De Benefícios E Incentivos Para A Redução Do Absenteísmo: Estudo De Caso $\mathrm{Na}$ Empresa Pedro Portella Nunes EPP. Revista Científica Multidisciplinar Núcleo do Conhecimento. Ano 06, Ed. 05, Vol. 03, pp. 156-175. Maio de 2021. ISSN: 2448-0959, Link de acesso: https://www.nucleodoconhecimento.com.br/administracao/reducaodo-absenteismo, DOI: 10.32749/nucleodoconhecimento.com.br/administracao/reducao-do-absenteismo

\section{RESUMO}

Diante dos fatores que levam a falta de motivação e aumento de absenteísmo, o objeto do estudo tem como base em primeira parte o diagnóstico organizacional realizado na empresa Pedro Portela EPP, localizada na cidade de Manaus, empresa do ramo de construção civil, indústria e comércio. O presente artigo tem como objetivo analisar o alto índice de absenteísmo gerado pela falta de benefícios e incentivos, elevando assim o baixo desempenho individual e coletivo dos colaboradores da empresa

\footnotetext{
${ }^{1}$ Graduanda do curso de Administração.

${ }^{2}$ Graduando do curso de Administração.

${ }^{3}$ Graduando do curso de Administração.

${ }^{4}$ Mestrado profissional em Engenharia de produção. Especialização em Gestão em Logística empresarial. Graduação em Administração com Ênfase em Marketing.
}

$\mathrm{RC}: 84518$

Disponível em: https://www.nucleodoconhecimento.com.br/administracao/reducao-doabsenteismo 
estudada. Fator esse que afeta diretamente a produtividade, resultados e a lucratividade dos negócios da empresa. A proposta de implementação de uma ferramenta de qualidade voltada para a melhoria de desempenho e para o fator motivacional, pretendendo obter o aumento da satisfação pessoal, baseado em problemas relacionados à falta de motivação identificados mediante pesquisas de campo. A pesquisa se caracteriza como um estudo de caso com características bibliográficas, através de referências de autores de livros, revistas e sites da internet. Tem natureza qualitativa e descritiva, uma vez que os dados foram coletados a fim de descrever os processos, relatos e os problemas da empresa identificados através entrevistas, relatórios de perguntas e respostas. A ferramenta utilizada para ação interventiva foi o $5 \mathrm{w} 2 \mathrm{~h}$, que tem por finalidade implementar cronogramas para melhorias e alcançar resultados positivos no setor de recursos humanos, setor este que apresentou pontos fracos e pontos mais fracos na avaliação de desempenho funcional, destacando a falta de motivação e elevando o alto índice de absenteísmo.

Palavra-chave: Absenteísmo, Benefícios, Motivação.

\section{INTRODUÇÃO}

Ao contrário do que se pensa, toda empresa por mais conceituada e acessível que seja, precisa elaborar estratégias para diminuir o absenteísmo, uma vez que o mesmo não se caracteriza apenas por faltas, atrasos ou saídas, mas também pela falta de motivação e estímulo de boas condições de trabalho, remuneração, reconhecimento profissional, incentivos, benefícios, satisfação interna, uma boa comunicação interna entre os líderes e os liderados etc.

Por meio de levantamentos realizados através de questionários, relatórios e entrevistas com os colaboradores, o presente artigo refere-se ao estudo de caso realizado na empresa Pedro Portela EPP. Onde a área de recursos humanos apresentou menor eficiência e mais criticidade em relação às demais áreas departamentais da empresa, elevando assim o alto índice de absenteísmo por

RC: 84518

Disponível em: https://www.nucleodoconhecimento.com.br/administracao/reducao-doabsenteismo 
desmotivação pela falta de benefícios e incentivos, haja em vista que funcionários desmotivados afetam diretamente no desempenho individual, coletivo e produtivo, resultando assim na sobrecarga de trabalho aos outros colaboradores.

A área de Recursos Humanos hoje não está somente voltada para admissão e demissão de pessoas, está interligada diretamente com todos os departamentos da empresa, desenvolvendo junto às outras áreas o capital humano e a estratégia para o bom funcionamento dos processos. É uma área muito importante para o desenvolvimento humano e para a retenção de talentos dentro da empresa.

Por meio do objetivo geral: incentivar os colaboradores para a redução do absenteísmo através de planos de benefícios. Quanto aos objetivos específicos: implementar plano de carreira, motivar os colaboradores com incentivos e benefícios, avaliar plano de carreira gerando oportunidades para os colaboradores com maior capacidade intelectual, controlar a taxa de absenteísmo estipulando regras para a manutenção dos benefícios.

A necessidade de implantação de uma ferramenta de qualidade, o $5 \mathrm{w} 2 \mathrm{~h}$, pode proporcionar o bem-estar social e profissional para todos os colaboradores da empresa Pedro Portella EPP através da implementação de propostas voltadas a aplicação dos planos de benefícios e incentivos, entre outros métodos motivacionais através de treinamentos e capacitação profissional, melhorando o desempenho individual e coletivo com todos motivados e gerando resultados positivos para empresa.

\section{FUNDAMENTAÇÃO TEÓRICA}

A fundamentação teórica se resume em pesquisas baseadas em artigos, livros, dissertações ou sites relacionados a um assunto específico e que fundamentam o estudo em questão. Servindo de horizonte e ponto de partida para o aprendizado e melhor interpretação das informações coletadas na empresa.

RC: 84518

Disponível em: https://www.nucleodoconhecimento.com.br/administracao/reducao-do$\underline{\text { absenteismo }}$ 
Como afirma Alencar e Borges (2014, p. 120): "A utilização dessas metodologias pode favorecer a autonomia do educando, despertando a curiosidade, estimulando tomadas de decisões individuais e coletivas, advindos das atividades essenciais da prática social e em contextos do estudante."

No artigo desenvolvido optamos como referencial bibliográfico os seguintes segmentos: Definição de motivação, métodos motivacionais, planos e benefícios, definição de absenteísmo, métodos para diminuição do absenteísmo, conceito de treinamento, definição de capital intelectual e definição de pesquisa de satisfação.

\subsection{DEFINIÇÃO DE MOTIVAÇÃO}

A motivação é caracterizada como algo que impulsiona um indivíduo ou equipe a realizar determinada tarefa ou alcançar determinado objetivo. E é muito importante para o bom desempenho na empresa, uma vez que está integrada ao alicerce da organização, que são seus colaboradores e tem consequências diretamente ligadas a produtividade. Uma empresa que motiva seus funcionários obtém um ganho alto de empenho e dedicação.

"Uma equipe motivada é uma equipe que acredita na construção de uma rede com todas as pessoas que interatuam com a organização (...) ter uma equipe motivada faz todos acreditarem que o impossível é possível. No fim, todos ganham com isso. " (LIPPI, 2014).

\subsubsection{MÉTODOS MOTIVACIONAIS}

Os métodos motivacionais que podem ser utilizados são relacionados a estímulos que podem ser oferecidos ao colaborador, seja por ganhos extras se houver alcance de metas, reconhecimento por conquistas, benefícios que melhorem sua qualidade de vida, qualificações que melhorem sua perspectiva de carreira e o estimulem a contribuir e agregar valor à empresa etc.

RC: 84518

Disponível em: https://www.nucleodoconhecimento.com.br/administracao/reducao-doabsenteismo 
Para Sobral e Peci (2013, p. 317):

As organizações são grupos de pessoas estruturados em torno de objetivos comuns. (...) de forma geral, é possível observar incongruências entre as necessidades dos indivíduos e os requerimentos da organização formal. Cabe ao administrador a tarefa de compatibilizar os objetivos de ambos.

Todos esses procedimentos direcionam o colaborador a se sentir responsável pelos resultados e bem recompensado por seu empenho individual.

\subsection{PLANOS E BENEFÍ́CIOS}

Planos e benefícios são medidas oferecidas como vantagens e méritos a funcionários que alcançam metas e obtêm bom desempenho. Esse mecanismo tem como objetivo estimular bons resultados e aumentar o grau de satisfação e reconhecimento para com os colaboradores.

Marras (2012, p.3) explica que:

Analisando os interesses da organização, o plano de benefícios deve atender as necessidades básicas dos funcionários de forma que mantenha baixos índices de absenteísmo e rotatividade e torne a empresa competitiva em relação à concorrência no mercado de trabalho. Pela ótica do colaborador, o plano de benefícios tem a finalidade de melhorar a sua qualidade de vida como parte integrante de sua remuneração.

A disponibilização de benefícios auxilia na retenção de talentos, aumenta a produtividade e diminui a rotatividade de pessoal, conhecida como turnover.

\subsection{DEFINIÇÃO DE ABSENTEÍSMO}

O absenteísmo é a frequente ausência, atraso ou desistência de funcionários na organização. Quando as taxas desse fenômeno se tornam altas e frequentes é o momento de a empresa determinar medidas para que diminua o índice. Uma empresa

RC: 84518

Disponível em: https://www.nucleodoconhecimento.com.br/administracao/reducao-doabsenteismo 
com taxas de absenteísmo altas tem baixa produtividade e não retém talentos, indicando falta de motivação e perspectiva em relação a seus funcionários.

Para Mondoni (2013 apud EJERE, 2010; FERNANDES et al., 2011): "O absenteísmo é formado pela soma dos períodos em que os empregados estão ausentes do trabalho, seja por falta, atraso ou algum outro motivo de força maior".

\subsubsection{MÉTODOS PARA DIMINUIÇÃO ABSENTEÍSMO}

Inúmeros fatores podem diminuir os altos índices de absenteísmo, entre eles a melhora do clima organizacional, inclusão de planos de carreira, novas políticas de reconhecimento, benefícios por metas individuais, bom treinamento, boa dinâmica de trabalho etc. Todos esses fatores auxiliam na retenção de talentos e no interesse de novos colaboradores aptos.

Como explica Melo e Santos (2012, p. 3):

A retenção é vista como a habilidade da organização em cultivar o indivíduo, é manter os funcionários essenciais. As práticas de retenção estão associadas à gestão de talentos, é a maneira como se deve investir em recursos financeiros e humanos que fazem com que o colaborador permaneça na empresa.

\subsection{CONCEITO DE TREINAMENTO}

O treinamento é essencial para que o processo de trabalho seja executado de forma eficiente e com mais qualidade, gerando maior lucro para a empresa e desenvolvendo maior empenho do colaborador, uma vez que o mesmo se sente apto e capaz de desenvolver o trabalho com base em treinamentos que agregam valor a sua capacitação.

Arroio (2019, p. 12) afirma que "a organização necessita preparar-se para oferecer ao seu colaborador um treinamento de qualidade, consciente de que a qualificação é fundamental para o seu desenvolvimento."

RC: 84518

Disponível em: https://www.nucleodoconhecimento.com.br/administracao/reducao-doabsenteismo 


\subsubsection{DEFINIÇÃO DE CAPITAL INTELECTUAL}

Capital intelectual é todo conhecimento gerado dentro da organização e que agregam resultados positivos a empresa. E pode ser obtido por meio de experiência, informação, estudos e cursos de capacitação voltados para a área de atuação. A valorização de seu capital intelectual é essencial para que a empresa se mantenha competitiva no mercado e obtenha bons resultados.

Conforme afirma Junior (2010, p. 32):

Muitas entidades ainda não perceberam que o foco do mercado atual é investir em seus ativos intangíveis, nas pessoas. O enfoque deixou de ser o maquinário e passou a ser o ser humano. Diante dessa situação faz-se necessário olhar o colaborador com outros olhos, não o de como se ele fosse uma despesa, mas sim um investimento.

\subsection{DEFINIÇÃO DE PESQUISA DE SATISFAÇÃO}

A pesquisa de satisfação interna tem como objetivo identificar como está o clima organizacional da empresa e o índice de satisfação de seus colaboradores. A partir do resultado da pesquisa é possível identificar a melhor ferramenta para melhorias da motivação na empresa uma vez que funcionários bem-motivados geram valor, aumentando a produtividade.

Para Alves et al. (2015) "O Clima Organizacional faz menção das percepções que os colaboradores de uma organização têm sobre ela e seu ambiente de trabalho."

\section{MATERIAIS E MÉTODOS}

Materiais e métodos são meios executados pelo pesquisador para estudo e uso de técnicas de pesquisa para se chegar à determinada conclusão teórica. Representa todo o processo desenvolvido no decorrer do estudo e pesquisa até a obtenção de resultados e comprovação por dados.

RC: 84518

Disponível em: https://www.nucleodoconhecimento.com.br/administracao/reducao-doabsenteismo 
Podendo variar sua metodologia conforme os métodos utilizados, o formato de pesquisa, a área de conhecimento, a coleta de informações e a abordagem que será desenvolvida.

Como explica Querino et al. (2018 p. 48):

O método é o procedimento que se segue para estabelecer o significado dos fatos e fenômenos para os quais se dirige o interesse científico, enquanto a técnica é o procedimento prático que se deve seguir para levar a cabo uma investigação.

\subsection{PROCEDIMENTOS METODOLÓGICOS}

Os procedimentos metodológicos estão relacionados ao método e a forma de pesquisa utilizada. O referido estudo de caso fez uso do método de pesquisa e coleta de dados dentro da empresa Pedro Portella Nunes EPP para obtenção de informações.

Conforme destaca Aragão e Neta (2017, p. 35):

Tão importante quanto escolher e justificar o método em sua pesquisa é narrar o percurso metodológico. Neste item são descritas todas as atividades práticas para garimpagem dos dados da pesquisa, isto é, as etapas de planejamento de cada item e subitem do projeto objetivando claramente a coleta dos dados.

A coleta de dados foi desenvolvida mediante a elaboração de questionários e entrevista com o proprietário, gerentes e colaboradores da empresa.

\subsubsection{QUANTO À NATUREZA}

A pesquisa tem natureza qualitativa, uma vez que foram utilizadas coletas de dados mediante visitas frequentes, entrevista com proprietários, gerentes e funcionários da produção, análise da estrutura e de documentos disponibilizados, assim como organogramas etc.

RC: 84518

Disponível em: https://www.nucleodoconhecimento.com.br/administracao/reducao-do$\underline{\text { absenteismo }}$ 
Os métodos qualitativos são aqueles nos quais é importante a interpretação por parte do pesquisador com suas opiniões sobre o fenômeno em estudo. Neles a coleta de dados muitas vezes ocorre por meio de entrevistas com questões abertas. (PEREIRA, 2018)

Além disso, o estudo se enquadra na pesquisa longitudinal no prospectivo, pois existe uma causa conhecida para o problema em questão e se procura uma solução para o problema.

\subsubsection{QUANTO AOS FINS}

Quanto aos fins, a pesquisa é classificada como descritiva uma vez que visa analisar os dados coletados, a fim de descrever processos, relatar os problemas existentes na empresa que precisam de soluções e identificar por que os problemas ocorrem.

Como afirma Knechtel (2014, p. 95) "Pesquisa descritiva: coleta de várias informações com grande número de variáveis, que serão reduzidas a quantificadores, que representam a dinâmica social, a fim de descrever o acontecimento dos fenômenos."

\subsubsection{QUANTO AOS MEIOS}

Enquanto aos meios, a pesquisa se caracteriza como um estudo de caso, uma vez que os dados foram coletados in loco e a partir disso foi feito uma análise da atual situação da empresa, efetivando assim um diagnóstico.

Conforme Vergara (2016, p. 75), o estudo de caso é a "investigação empírica realizada no local onde ocorre ou ocorreu um fenômeno ou que dispõe de elementos para explicá-lo. Pode incluir entrevistas, aplicação de questionários, testes e observação participante ou não".

A pesquisa também possui características bibliográficas, uma vez que será utilizado o uso de materiais como artigos, livros e pesquisas publicadas anteriormente como

RC: 84518

Disponível em: https://www.nucleodoconhecimento.com.br/administracao/reducao-doabsenteismo 
base para compreensão do setor de recursos humanos e motivação da equipe em uma empresa.

Assim como explica Marconi e Lakatos (2019, p. 36) "Pesquisa bibliográfica é um tipo específico de produção científica: é feita com base em textos, como livros, artigos científicos, ensaios críticos, dicionários, enciclopédias, jornais, revistas, resenhas, resumos."

\subsection{CARACTERÍSTICAS DA EMPRESA}

A Pedro Portella Nunes EPP é uma empresa brasileira do ramo de indústria e comércio, situada na cidade Manaus/AM. Localizada na Rua Cassia Baiana, oㅡ 613, no Bairro Jorge Teixeira de CEP 69.088-474, Zona Leste.

Sob CNPJ 21.830.777/0001-53, a natureza do negócio corresponde a comércio varejista de materiais de construção em geral. Executando atividades como fabricação de estruturas pré-moldadas de concreto armado, em série e sob encomenda.

Possuem um catálogo extenso de produtos, como: Paver, cobogó, bloco de concreto de diversos tamanhos e produzidos conforme necessidade de cada estrutura, mourão, laje pré-moldada, meio fio, concregrama. Além disso, ainda disponibilizam opções de personalização de produtos, produzidos conforme necessidade do cliente.

Desta forma, se caracteriza como empresa de fabricação de artefatos de cimento para uso na construção e serviços de engenharia. E que buscam como objetivo o lucro, o crescimento duradouro e a estabilidade financeira.

\section{RESULTADOS E DISCUSSÕES}

Mediante implementação da ferramenta Radar, escolhida na elaboração do Diagnóstico Organizacional foi possível identificar a média de desempenho da empresa na sua estrutura geral e em relação às suas áreas funcionais que são,

RC: 84518

Disponível em: https://www.nucleodoconhecimento.com.br/administracao/reducao-doabsenteismo 
respectivamente: Marketing, Produção e Operações, Finanças, Recursos Humanos, Administração e Logística e pode ser observado no gráfico 01: Medição de desempenho.

Gráfico 01: Medição de Desempenho

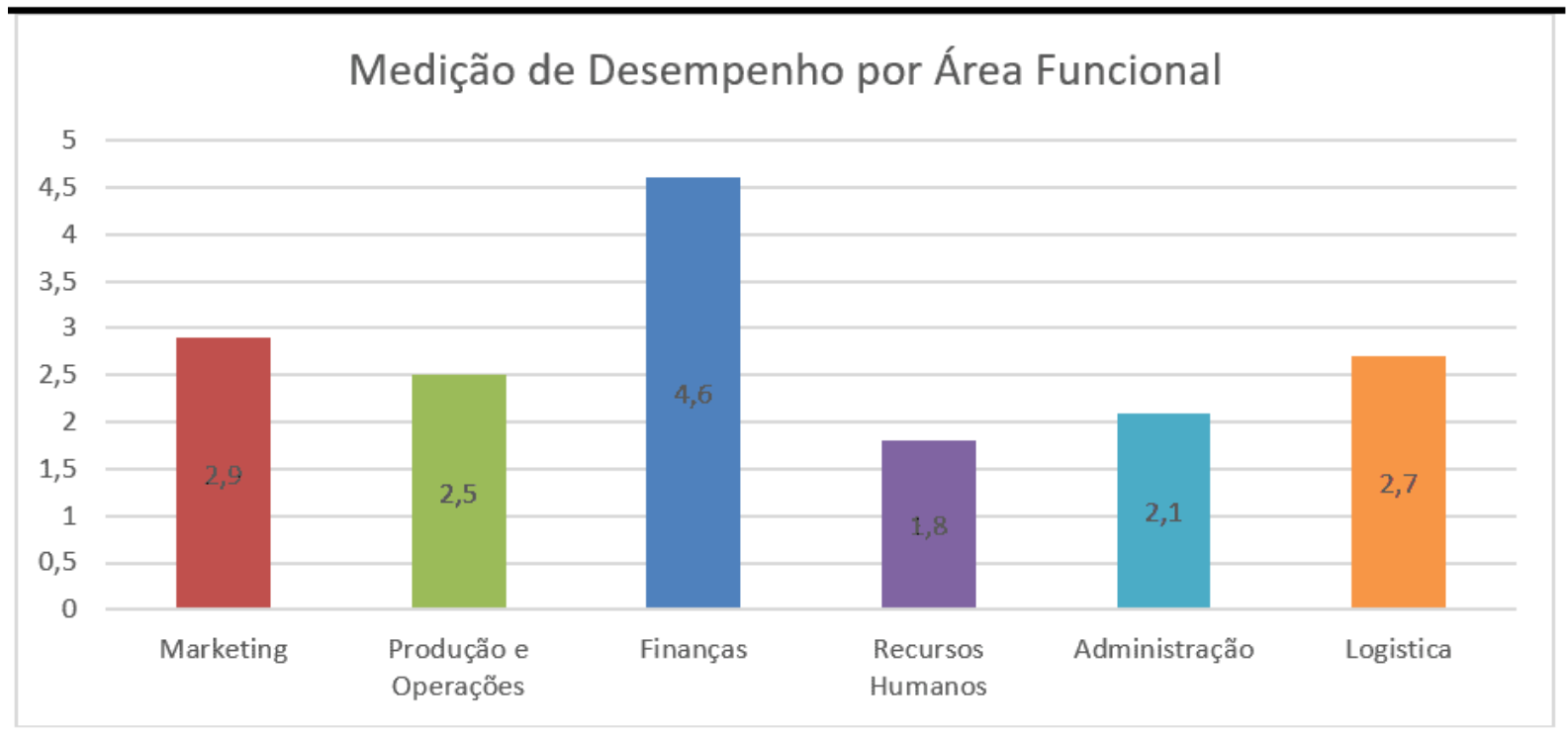

Fonte: Elaborado pelos autores com base na coleta de dados (2021)

Desta forma, observou-se no gráfico 01 que a empresa Pedro Portella Nunes apresenta melhor desempenho na área de Finanças, porém maior deficiência em sua área de Recursos Humanos, seguidos da área de Gestão Administrativa e área de Produção e Operações com desempenhos médios. O que significa que a empresa precisa implementar ferramentas e programas de melhorias nesses departamentos para que possa obter resultados satisfatórios. Como podemos ver no quadro 01 abaixo.

Quadro 01: Área crítica Recursos Humanos

\section{\begin{tabular}{l|l} 
ÁREA FUNCIONAL & NÍVEL OU GRAU DE AVALIAÇÃO
\end{tabular}}

RC: 84518

Disponível em: https://www.nucleodoconhecimento.com.br/administracao/reducao-doabsenteismo 


\begin{tabular}{|c|c|c|c|c|c|c|}
\hline \multicolumn{2}{|c|}{ RECURSOS HUMANOS } & \multirow[t]{2}{*}{$\begin{array}{l}\text { Ponto } \\
\text { muito } \\
\text { forte } 5\end{array}$} & \multirow[t]{2}{*}{$\begin{array}{l}\text { Ponto } \\
\text { forte } 4\end{array}$} & \multirow{2}{*}{$\begin{array}{l}\text { Ponto } \\
\text { médio } \\
3 \\
x\end{array}$} & \multirow[t]{2}{*}{$\begin{array}{l}\text { Ponto } \\
\text { fraco } 2\end{array}$} & \multirow[t]{2}{*}{$\begin{array}{l}\text { Ponto } \\
\text { muito } \\
\text { fraco } 1\end{array}$} \\
\hline 1 & $\begin{array}{l}\text { Mão de obra operacional } \\
\text { suficiente }\end{array}$ & & & & & \\
\hline 2 & $\begin{array}{l}\text { Recrutamento e } \\
\text { treinamento adequados }\end{array}$ & & & & $x$ & \\
\hline 3 & $\begin{array}{l}\text { rotatividade de pessoal } \\
\text { normalizada }\end{array}$ & & & & $x$ & \\
\hline 4 & $\begin{array}{l}\text { Programas de motivação } \\
\text { para os trabalhadores }\end{array}$ & & & & & $x$ \\
\hline 5 & $\begin{array}{l}\text { Desenvolvimento técnico } \\
\text { profissional }\end{array}$ & & & & $x$ & \\
\hline 6 & $\begin{array}{l}\text { Satisfação dos } \\
\text { colaboradores quanto ao } \\
\text { ambiente de trabalho }\end{array}$ & & & & & $x$ \\
\hline 7 & $\begin{array}{l}\text { Programa de prevenção a } \\
\text { acidentes no local de } \\
\text { trabalho }\end{array}$ & & & $x$ & & \\
\hline 8 & $\begin{array}{l}\text { Programa de } \\
\text { recrutamento e seleção } \\
\text { estruturado }\end{array}$ & & & & $x$ & \\
\hline 9 & $\begin{array}{l}\text { Taxas de absenteísmo } \\
\text { controlada }\end{array}$ & & & & & $x$ \\
\hline 10 & $\begin{array}{l}\text { Metas individuais de } \\
\text { desempenho para cada } \\
\text { colaborador }\end{array}$ & & & & & $x$ \\
\hline TO & TAL ( $(\Sigma)$ & 0 & 0 & 6 & 8 & 4 \\
\hline
\end{tabular}

RC: 84518

Disponível em: https://www.nucleodoconhecimento.com.br/administracao/reducao-doabsenteismo 


\begin{tabular}{|c|c|c|c|c|c|}
\hline $\begin{array}{l}\text { MÉDIA POR GRAU (POR } \\
\text { COLUNA) }\end{array}$ & 0 & 0 & 0,6 & 0,8 & 0,4 \\
\hline DESEMPENHO DA ÁREA & 1,8 & & & & \\
\hline
\end{tabular}

Fonte: Elaborado pelos autores com base na coleta de dados (2021)

Conforme apresentado no Quadro 01, constatou-se que o ponto mais fraco da área funcional de Recursos Humanos são: Programas de motivação para os trabalhadores, satisfação dos colaboradores, taxas de absenteísmo controladas e metas individuais de desempenho para cada colaborador.

Pode-se analisar como uma deficiência grave em uma área importante para o bom desempenho produtivo da empresa, uma vez que os funcionários estão diretamente envolvidos no resultado produtivo e na qualidade dos produtos fabricados.

Desta forma, entra a principal questão para busca de melhorias na empresa Pedro Portella Nunes EPP: Como a implementação de incentivos e benefícios podem colaborar para a motivação e a redução do absenteísmo?

\subsection{PLANEJAMENTO DAS AÇÕES}

Planejar uma ação requer de maneira organizada e documentada o planejamento para o atingimento dos resultados positivos de um ou mais problemas com finalidade de atingir as metas e objetivos.

Desta forma, objetivamos 5 ações interventivas para serem implementadas no planejamento da empresa, que foram: Aplicar treinamentos para saúde e segurança ocupacional, programar cursos de capacitação profissional, analisar a proposta de planos e incentivos, desenvolver avaliação de desempenho individual e implementar pesquisa de clima organizacional. Determinando sua cronologia, duração e o custo das medidas oferecidas. Como podemos observar no Quadro 02.

RC: 84518

Disponível em: https://www.nucleodoconhecimento.com.br/administracao/reducao-doabsenteismo 
Quadro 02: Ações interventivas

\begin{tabular}{|c|c|c|c|c|}
\hline & Ações Interventivas & Cronologia & Duração & Custo \\
\hline 01 & $\begin{array}{l}\text { Aplicar treinamentos para saúde e } \\
\text { segurança ocupacional. }\end{array}$ & Abril /2021 & 5 dias & $\begin{array}{l}R \$ \\
1.000,00\end{array}$ \\
\hline 02 & $\begin{array}{l}\text { Programar cursos de capacitação } \\
\text { profissional. }\end{array}$ & Abril /2021 & 30 dias & $\begin{array}{l}R \$ \\
3.000,00\end{array}$ \\
\hline 03 & $\begin{array}{l}\text { Analisar a proposta de planos de } \\
\text { benefícios e incentivos. }\end{array}$ & Junho /2021 & 30 dias & $\begin{array}{l}R \$ \\
5.000,00\end{array}$ \\
\hline 04 & $\begin{array}{l}\text { Desenvolver avaliação de } \\
\text { desempenho individual. }\end{array}$ & Junho /2021 & 1 dia & $\mathrm{R} \$ 800,00$ \\
\hline 05 & $\begin{array}{l}\text { Implementar pesquisa de clima } \\
\text { organizacional. }\end{array}$ & $\begin{array}{l}\text { Dezembro } \\
\text { /2021 }\end{array}$ & 2 dias & $\mathrm{R} \$ 200,00$ \\
\hline \multicolumn{4}{|c|}{ Total: } & $\begin{array}{l}R \$ \\
10.000,00\end{array}$ \\
\hline
\end{tabular}

Fonte: Elaborado pelos autores (2021)

A ferramenta utilizada para a solução das etapas foi o $5 \mathrm{w} 2 \mathrm{~h}$, que é uma ferramenta de qualidade que identifica as ações e as responsabilidades de execução, buscando respostas às sete perguntas fundamentais: o que? por quê? onde? quando? quem? como? e quanto?

Conforme explica Seleme e Stadler (2008, p. 43):

Quando declara que o uso da ferramenta 5 Por Quê para estudo e análise de determinado questionamento auxilia na identificação do problema diretamente na sua raiz, na causa que o gera. Afirma ainda que se é usado o "Por quê" quantas vezes forem necessárias, de forma a estruturar o problema melhorando a visualização do mesmo.

RC: 84518

Disponível em: https://www.nucleodoconhecimento.com.br/administracao/reducao-doabsenteismo 


\subsubsection{APLICAR TREINAMENTO PARA SAÚDE E SEGURANÇA OCUPACIONAL}

É importante envolver e conscientizar os colaboradores sobre as causas dos acidentes, os riscos, os perigos e os impactos ao meio ambiente através da realização de uma SIPATMA (Semana Interna de Prevenção de Acidentes de Trabalho e Meio Ambiente). O principal intuito é prevenir e conscientizar os colaboradores sobre a prevenção de acidentes e doenças que podem ser evitadas, além de preservar os recursos naturais e a preocupação com o meio ambiente por meio de palestras, dinâmicas e gincanas direcionadas à prevenção de acidentes e doenças ocupacionais, e a preservação do meio ambiente.

Marras (2015, p. 133) explica que: "O treinamento produz um estado de mudança no conjunto de Conhecimentos, Habilidades e Atitudes ( $\mathrm{CHA})$ de cada trabalhador uma vez que implementa ou modifica a bagagem particular de cada um."

Quadro 03: 5w2h - Implementar treinamento para saúde e segurança ocupacional

\section{Aplicar treinamento para saúde e segurança ocupacional}

O que? Treinamento para orientação aos colaboradores quanto aos riscos e perigos que podem ser ocasionados no ambiente de trabalho.

Por quê? Para garantir a saúde e a segurança dos colaboradores.

Onde? Empresa Pedro Portella Nunes EPP.

Quando? Primeira semana de abril de 2021.

Quem? Departamentos de produção e administrativo

Como? Conscientizando os colaboradores através da SIPATMA (Semana Interna de Prevenção de Prevenção de Acidentes no Trabalho e Meio Ambiente).

Quanto? R\$1.000,00 
Como demonstrado no quadro 03 , optou-se por aplicar treinamento e orientação sobre a saúde e segurança ocupacional dos colaboradores, visando a diminuição de acidentes no setor da produção, oferecendo maior segurança ao profissional e alertando-os sobre a importância do uso correto dos equipamentos de proteção individual, os EPI's. Essa medida terá o valor de $\mathrm{R} \$ 1.000,00$ e duração de 5 dias de treinamento.

\subsubsection{PROGRAMAR CURSOS DE CAPACITAÇÃO PROFISSIONAL}

Poder proporcionar aos colaboradores uma formação e capacitação profissional, aumentando assim o seu capital intelectual. Com os cursos sendo online, a empresa terá um custo reduzido e poderá controlar a frequência dos colaboradores, já que muitos se recusam a participar de cursos presenciais devido ao desgaste físico causado pela jornada diária do serviço. Além disso, a empresa pode economizar no transporte e nos custos com materiais didáticos, já que os cursos online já disponibilizam todo o material de estudo.

De acordo com Moreira (2012, p. 39):

Para investir no capital humano, de modo a obter resultados satisfatórios, é necessário entender seu comportamento dentro da organização, já que o modo como as pessoas agem, pensam, expressam sentimentos é um dos principais elementos - senão o principal - que interferem na construção do clima organizacional benéfico.

Quadro 04: 5w2h - Programar cursos de capacitação profissional

\section{Programar cursos de capacitação profissional}

\section{O que? Cursos de capacitação profissional.}

Por quê? Para ajudar no capital intelectual, pessoal e profissional.

Onde? Sala de treinamento da empresa Pedro Portela EPP.

Quando? Segunda semana de abril de 2021.

RC: 84518

Disponível em: https://www.nucleodoconhecimento.com.br/administracao/reducao-doabsenteismo 
Quem? Todos os colaboradores operacionais e administrativos.

Como? Será criada uma sala de Informática e treinamento.

Quanto? $\quad \mathrm{R} \$ 3.000,00$

Fonte: Elaborado pelos autores (2021)

A medida de intervenção proposta no quadro 04 refere-se a implementar programas de cursos de capacitação com o intuito de aumentar o capital intelectual e ampliar os conhecimentos de seus funcionários. Resultando em uma maior perspectiva de crescimento na empresa e melhorando o desempenho individual do colaborador. Os cursos aconteceriam de forma online nas dependências da empresa após o horário de expediente, com o custo de $\mathrm{R} \$ 3.000$ e duração de 30 dias.

\subsubsection{ANALISAR A PROPOSTA DE PLANO DE BENEFícIOS E INCENTIVOS}

Desenvolver um plano de benefícios para funcionários contribui para um ambiente organizacional mais humano e acolhedor, uma vez que são elaborados conforme as necessidades dos seus colaboradores. Essa ação resulta em retenção de talentos e motivação, sendo usado como estímulo para melhores resultados e desempenho.

Um sistema de compensação eficiente deve ser adequado conforme a legislação do salário-mínimo e também com as demais legislações alinhadas com os salários de mercados [...] adequado com o cargo, tornando o sistema justo, concedendo incentivo, méritos e aumentos, sem esquecer do equilíbrio entre a organização e o empregado (ROTHMANN; COOPER, 2009, p. 202).

Quadro 05: 5w2h - Analisar a proposta de planos de benefício e incentivos

\section{Analisar a proposta de plano de benefícios e incentivos}

O que? Benefícios e incentivos

Por quê? Para aumentar a motivação dos colaboradores

RC: 84518

Disponível em: https://www.nucleodoconhecimento.com.br/administracao/reducao-doabsenteismo 


\author{
Onde? Na empresa Pedro Portela EPP. \\ Quando? Primeira semana Junho de 2021 \\ Quem? Todos os colaboradores da Pedro Portela EPP. \\ Como? Estabelecendo normas para manutenção dos benefícios e incentivos \\ Quanto? $\mathrm{R} \$ 5.000,00$
}

Fonte: Elaborado pelos autores (2021)

Opta-se no quadro 05 por incluir benefícios compulsórios, que são aqueles exigidos pelas leis trabalhistas e os benefícios espontâneos que são aqueles determinados pela própria empresa, podendo ser concedidos em dinheiro, cestas básicas, banco de horas, assistência médica etc. Sendo estipulado o ganho do benefício aos funcionários que tenham cumprido metas ou não tenham tido faltas no mês, por exemplo.

Essa medida terá custo de $\mathrm{R} \$ 5.000,00$ e será feita todo mês, proporcionando incentivos para que os colaboradores busquem alcançar objetivos de interesse da empresa para serem contemplados com os benefícios.

\title{
4.1.4 DESENVOLVER AVALIAÇÃO DE DESEMPENHO INDIVIDUAL
}

A avaliação de desempenho organizacional tem como objetivo analisar o desempenho dos colaboradores de determinada empresa de forma individual e objetiva, facilitando o diagnóstico e a percepção de como está o dinamismo e o empenho do colaborador e da equipe, e se é condizente com a cultura da empresa. Desta forma, se torna possível desenvolver métodos para estimular os colaboradores que mostraram desempenho inferior e serve como incentivo individual para alcançar bons resultados e assim ser reconhecido de forma positiva.

RC: 84518

Disponível em: https://www.nucleodoconhecimento.com.br/administracao/reducao-doabsenteismo 
Avaliação de desempenho é um processo que serve para julgar ou estimar o valor, a excelência e as competências de uma pessoa ou equipe. É o processo que mede o desempenho do funcionário e configura o grau em que ele alcança os requisitos do seu trabalho. (CHIAVENATO, 2014).

Quadro 06: 5w2h - Desenvolver avaliação de desempenho individual

\section{Desenvolver avaliação de desempenho individual}

O que? Avaliação de desempenho individual.

Por quê? Para medir o nível de performance dos colaboradores.

Onde? Na Empresa Pedro Portela EPP.

Quando? Quarta semana de junho de 2021.

Quem? Todos os colaboradores da Pedro Portela EPP.

Como? Avaliando as competências técnicas e comportamentais dos colaboradores.

Quanto? $\mathrm{R} \$ 800,00$

Fonte: Elaborado pelos autores (2021)

A intervenção esclarecida no quadro 06, visa monitorar de forma precisa e constante o desenvolvimento e progresso do colaborador de forma individual. Resultará em empenho dos funcionários para obter resultados positivos para sua avaliação. Será desenvolvida 1 vez no mês e terá custo de $\mathrm{R} \$ 800,00$.

\subsubsection{IMPLEMENTAR PESQUISA DE CLIMA ORGANIZACIONAL}

A inclusão de uma pesquisa de clima organizacional consiste em identificar o grau de satisfação e harmonia existente na organização relacionadas aos fatores envolvidos em sua rotina diária, visando apurar o que os colaboradores sentem em relação a empresa e o que pode ser feito para melhorar a sua qualidade de vida, gerando

RC: 84518

Disponível em: https://www.nucleodoconhecimento.com.br/administracao/reducao-doabsenteismo 
confiabilidade, respeito, qualidade na produção, motivação e uma melhor gestão, pois faz com que as visões de todos sejam respeitadas e levadas em consideração.

Siqueira (2008, p. 31) afirma que:

Um melhor conhecimento do clima organizacional pode colaborar para a melhoria da qualidade de vida do homem no trabalho, para a otimização do desempenho das organizações e esclarecimentos das relações entre esta e outras variáveis do comportamento organizacional.

Quadro 07: 5w2h - Implementar pesquisa de clima organizacional

\section{Implementar pesquisa de clima organizacional}

O que? Pesquisa de clima organizacional.

Por quê? Para entender melhor a cultura organizacional, os pontos fortes e os pontos fracos da empresa, avaliar o sistema de gestão.

Onde? Na empresa Pedro Portela EPP.

Quando? Terceira semana de dezembro de 2021

Quem? Todos os departamentos administrativos e operacionais.

Como? Identificando o ambiente interno da empresa, avaliando o desempenho e a produtividade dos colaboradores, a cultura aplicada pela empresa e os seus propósitos e o seu sistema de gestão.

Quanto? $R \$ 200,00$

Fonte: Elaborado pelos autores (2021)

A medida relatada no quadro 07 está relacionada ao monitoramento de satisfação do colaborador, buscando entender seus pontos fracos e fortes em relação ao ambiente organizacional, proporcionando maior satisfação e confiança do funcionário que será ouvido e entendido. O custo dessa medida será de $R \$ 200,00$ referentes ao gasto com papéis, impressão e canetas para preenchimento do formulário da pesquisa interna. 
Portanto, medidas simples podem alavancar os processos produtivos da empresa. Através da implementação das medidas apresentadas anteriormente será possível diminuir os índices de absenteísmo e aumentar o grau de satisfação entre seus colaboradores. Visando progresso, desenvolvimento intelectual, melhorias no clima organizacional, melhoria na qualidade de vida de seus funcionários através de benefícios e retenção de talentos.

\section{CONSIDERAÇÕES FINAIS}

Diante das constantes pesquisas e estudos que foram realizados na empresa Pedro Portella Nunes EPP, foi constatado que a grande problemática se encontrava no setor de Recursos Humanos, relacionados ao grande índice de absenteísmo e a falta de motivação entre os colaboradores. Desta forma, se iniciou o estudo voltado para uma proposta de implementação de planos de benefícios e incentivos para a redução do absenteísmo.

Desta forma, o artigo teve como objetivo analisar a problemática causada por esse fator que pode gerar impactos diretamente ligados aos resultados, metas, objetivos e na lucratividade da empresa diante da falta de motivação ocasionada pela falta de benefícios e incentivos para tornar-se um ambiente de trabalho saudável.

Tendo em vista a problemática identificada, a pesquisa teve como objetivo geral incentivar os colaboradores para a redução do absenteísmo através de planos de benefícios. E teve sucesso em sua busca, pois foi possível identificarmos as inúmeras maneiras de implementar métodos motivacionais, assim como implementar plano de carreira, incentivos e benefícios para motivar os colaboradores, avaliar plano de carreira abrindo oportunidades para os colaboradores mais capacitados e controlar a taxa de absenteísmo, estipulando regras para a manutenção do recebimento dos benefícios e incentivos.

RC: 84518

Disponível em: https://www.nucleodoconhecimento.com.br/administracao/reducao-doabsenteismo 
Assim, após a implantação da ferramenta escolhida, que foi a $5 \mathrm{w} 2 \mathrm{~h}$, foi possível diagnosticarmos as medidas necessárias para melhorias motivacionais e diminuição do absenteísmo alinhados a uma proposta realista e com custo e benefícios coerentes, uma vez que, por um valor plausível, a empresa poderá ter resultados positivos significativos e que alavancará o processo produtivo e crescimento pessoal e intelectual de seus colaboradores.

\section{REFERÊNCIAS}

ALENCAR, G.; BORGES, T. S. Metodologias ativas na promoção da formação crítica do estudante: o uso das metodologias ativas como recurso didático na formação crítica do estudante do ensino superior. Cairu em Revista. Jul/Ago 2014.

ALVES, A. C. et al. Que clima é esse? avaliação da percepção do clima organizacional de uma concessionária de caminhões. Revista Campo do saber, Vol.1, N¹, 2015.

ARAGÃO, J. W. M. NETA, M. A. H. M. Metodologia Científica. Salvador: UFBA, Faculdade de Educação, Superintendência de Educação a Distância, ISBN: 978-858292-131-9, 2017.

ARROIO, G. B. Processo empírico de treinamento e desenvolvimento de pessoas: análise de uma empresa no setor de produtos e serviços automotivos em Uberlândia, MG. 23 f. Trabalho de Conclusão de Curso (Graduação em Administração) - Universidade Federal de Uberlândia, Uberlândia, 2019.

CHIAVENATO, I. Gestão de Pessoas: e o novo papel dos recursos humanos nas organizações. $4^{\circ}$ ed. Rio de Janeiro: Elsevier, 2014.

JUNIOR, I. C. L.; SILVA, A. J. C. da. A implementação do sistema de benefícios nas organizações como fator de desenvolvimento empresarial consistente - um panorama da região sul fluminense. In: II Simposio de excelência em gestão e

RC: 84518

Disponível em: https://www.nucleodoconhecimento.com.br/administracao/reducao-doabsenteismo 
tecnologia: associação educacional Dom Bosco, 2006, Rio de Janeiro, SEDeT, 2006. Disponível em: Acesso em: 12 de março de 2021.

JUNIOR, N. da R. F. Retenção de Talentos: Consideração de aspectos determinantes na empresa Volvo do Brasil Veículos S/A. Ponta Grossa: UTFPR, 2010. Disponível em: <http://docplayer.com.br/2754063-Retencao-de-talentosconsideracao-de-aspectos-determinantes-na-empresa-volvo-do-brasil-veiculos-sa.html>

KNECHTEL, M. do R. Metodologia da pesquisa em educação: uma abordagem teórico-prática dialogada. Curitiba: Intersaberes, 2014.

LAKATOS, E. M.; MARCONI, M. A. Fundamentos de metodologia científica. São Paulo: Atlas, 8. ed. [3. Reimpr.], 2019.

LIPPI, F. Porque sua empresa ganha mais com uma equipe motivada. Exame, 2014. Disponível em:< http://exame.abril.com.br/pme/noticias/por-que-sua-empresaganha-mais-com-uma-equipe-motivada/>. Acesso em 15/03/2021.

MARRAS, J. P. Administração de recursos humanos: do operacional ao estratégico. 15. ed. São Paulo: Saraiva, 2015.

MARRAS, J. P. Administração de remuneração. São Paulo: Pearson Education do Brasil, 2012. Disponível em: Acesso em: 16 março de 2021.

MATOS, G. G. de. Comunicação Empresarial sem Complicação. 2ª Edição. São Paulo: Manole, 2009.

MELLO, D. A.; SANTOS, T. S. Variáveis de Retenção no Setor Bancário. In: XIII Seminários em Administração, 2012. São Paulo. Anais... Disponível em:/<http://www.progep.org.br/MelhoresEmpresas/InfoDocs/Vari\%C3\%A1veis\%20d 
e\%20Reten\%C3\%A7\%C3\%A30\%20no\%20Setor\%20Banc\%C3\%A1 rio.pdf?Mobile= 1>. Acesso em: 20 de março de 2021.

MONDONI, V. M. A Relação do Bem-estar no Trabalho com o índice de Absenteísmo: um estudo em uma empresa no ramo de confecção. Vitória: FUCAPE, 2013.

MOREIRA, E. G. Clima Organizacional. Curitiba, Paraná: IESDE, 2012.

MOREIRA, J. C. T. Liderança: A Execução como parte, Melhor Gestão de Pessoas, Ano 21, № 310, p.224, setembro 2013.

PEREIRA, L. S. Motivação de Indivíduos e Grupos de Trabalho. Maringá-Pr.: UniCesumar, 2018.

ROBBINS, S. P. et al. Comportamento Organizacional. 14ạ. ed. São Paulo: Pearson Prentice Hall, 2010; SLIDESHARE. Avaliação de Desempenho Com Foco em Competências. Disponível em: Acesso: 20 março de 2021.

ROBBINS, S. P. et al. Comportamento organizacional: teoria e prática no contexto brasileiro. 14. ed. São Paulo: Pearson Prentice Hall, 2013.

ROTHMANN, I.; COOPER, C. Fundamentos de psicologia organizacional e do trabalho. Rio de Janeiro: Elsevier, 2009.

SELEME, R.; STADLER, H. Controle da Qualidade: as Ferramentas Essenciais. Curitiba: IBPEX, 2008.

SIQUEIRA, M. M. M. Medidas do comportamento organizacional: ferramentas de diagnóstico e de gestão. Porto Alegre: Artmed, 2008.

SOBRAL, F.; PECl, A. Administração: teoria e prática no contexto brasileiro. 2. Ed. São Paulo: Pearson Education do Brasil, 2013.

RC: 84518

Disponível em: https://www.nucleodoconhecimento.com.br/administracao/reducao-doabsenteismo 
VERGARA, S. C. Projetos e relatórios de pesquisa em Administração. 7. ed. São Paulo: Atlas, 2016.

Enviado: Março, 2021.

Aprovado: Maio, 2021. 